\title{
Bucket wheel excavator cutting tooth stress and deformation analysis during operation using Finite Elements Method (FEM)
}

\begin{abstract}
In the case of bucket wheel excavators, the cutting process is influenced by the forces opposing the working elements and cutting tools. These forces determine the choice of machines and their parameters as well as the operating method [1, 2]. Studies conducted on the failure causes of mechanical parts show that the cutting and loading systems cause the highest rate of failure - about 32\% of all recorded mechanical failures [3]. In this paper, we will use the Finite Element Method (FEM) to analyze the deformations and stresses acting on the cutting teeth mounted on the rotor of BWEs. For this, SolidWorks ${ }^{\circledR}$ software was used, both as a CAD tool to design the teeth as well as to model and simulate the phenomena.
\end{abstract}

Key words: BWE, rotor, cutting teeth, cutting tooth support, FEM, force, strain, deformation

\section{STEPS FOR A FEM APPROACH}

The starting point for any project using FEM and simulation is a model that can be a part or a set of parts. First, the characteristics of the material(s) of the parts, the tasks to which they are subjected, and the restrictions are defined [4]. Subsequently, as with any FEM-based analysis tool, the geometry of the model is divided into relatively small entities called finite elements. Creating the elements is commonly called meshing [5].

The degrees of freedom (DOF) of a node in a finite element mesh define the ability of the node to perform translation and rotation. The number of degrees of freedom that a node possesses depends on the element type. In SolidWorks ${ }^{\circledR}$ simulation, the nodes of the solid elements have three degrees of freedom, while those of the shell elements have six degrees of freedom.

Creating the mesh network often requires changes in the CAD geometry:

- cancelling - the process of removing parts of the geometry that are insignificant to the analysis, such as fillets or bevels,
- idealization - a more aggressive process of changing the geometry; for example, thin walls are replaced with surfaces or beams replaced by lines, - cleaning - necessary for the geometry to satisfy the requirements imposed by the meshing.

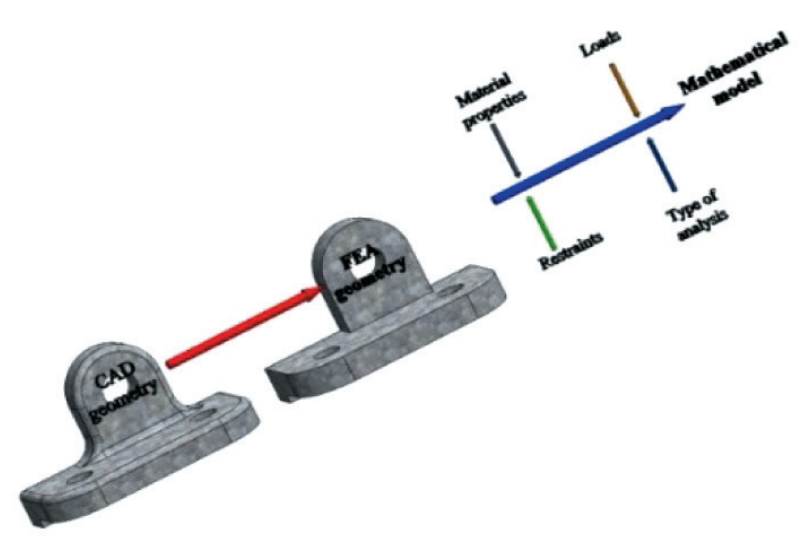

Fig. 1. Creation of mathematical model

Creating a mathematical model consists of: modifying the CAD geometry (i.e., Fig. 1 - we removed the fillets), defining the loads and strains, imposing the restrictions, defining the properties of the material, 
and determining the type of analysis (static, dynamic, etc.) to be carried out [6]. The properties of the material, the tasks, and the restrictions imposed on the model make up the input information for a certain type of analysis.

The mathematical model based on the FEM geometry, the information and properties of the material, the requirements to which the model is subjected, and the imposed restrictions can be divided into finite elements using the meshing process (Fig. 2).

The discreet loads and restrictions are applied to the nodes of the finite element mesh [7].

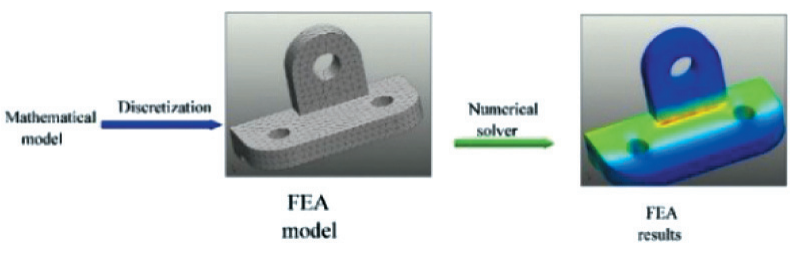

Fig. 2. Building FEM model

Often, the most difficult step of an FEM study is the analysis of the results. The correct interpretation of the results implies the understanding of all of the simplifications and errors that they induce in the first three stages: defining the mathematical model, the meshing, and coming up with the solution.

\section{VON MISES YIELD CRITERION}

The von Mises stress test criterion (also known as the Huber criterion) is a stress test that represents all six components of a general 3-D state (Fig. 3).

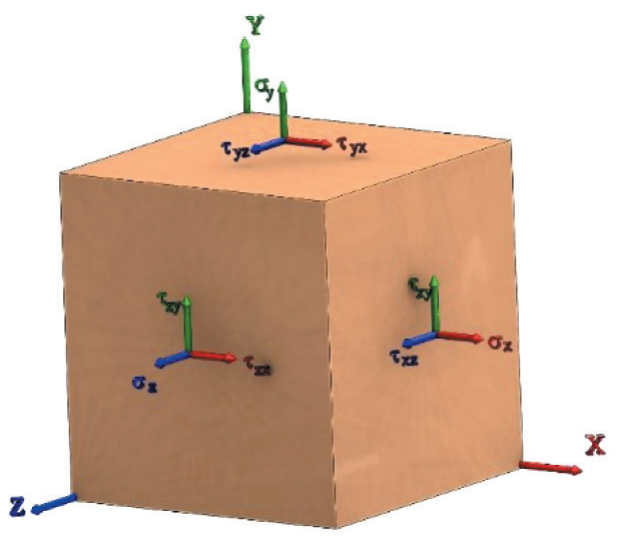

Fig. 3. General state of stresses

The general stress is represented by three normal stresses $\left(\sigma_{x}, \sigma_{v}, \sigma_{z}\right)$ and six tangential or shear stresses. Due to the symmetry of the shear stresses, the 3D general tension state is characterized by six components: $\sigma_{x}, \sigma_{v}, \sigma_{z}$ and $\tau_{x y}=\tau_{y x}, \tau_{y z}=\tau_{z y}, \tau_{x z}=\tau_{z x}$. Von Mises stress can be expressed by the following equation:

$$
\sigma_{v m}=\sqrt{\begin{array}{l}
0.5 \cdot\left[\left(\sigma_{x}-\sigma_{y}\right)^{2}+\left(\sigma_{y}-\sigma_{z}\right)^{2}+\right. \\
\left.\left(\sigma_{z}-\sigma_{x}\right)^{2}\right]+3 \cdot\left(\tau_{x y}^{2}+\tau_{y z}^{2}+\tau_{z x}^{2}\right)
\end{array}}
$$

Von Mises stress is frequently used for the structural safety analysis of materials with elasto-plastic properties (such as steel or aluminum alloys). In theory, a ductile material yields when the von Mises stress equals the permissible stress limit. In most cases, the flow limit is used as a stress limit. According to the von Mises criterion in the case of failures, the factor of safety $(F O S)$ is expressed as follows:

$$
F O S=\frac{\sigma_{\text {limit }}}{\sigma_{v m}}
$$

where $\sigma_{\text {limit }}$ is the flow limit.

\section{GEOMETRIC PARAMETERS OF TEETH OF BWES}

The geometry of the cutting teeth of BWEs is influenced by:

- the functional parameters of the excavator,

- the constructive parameters of the cups (Fig. 4) and rotor (Fig. 5),

- the shape and type of cutting teeth used,

- the type of excavated material,

- cost.

There are two types of cutting teeth: 1 - chisel-shaped cutting teeth (used on BWEs); 2 - conically shaped cutting teeth (used on both single-bucket excavators and shearer-loader machines) [10].

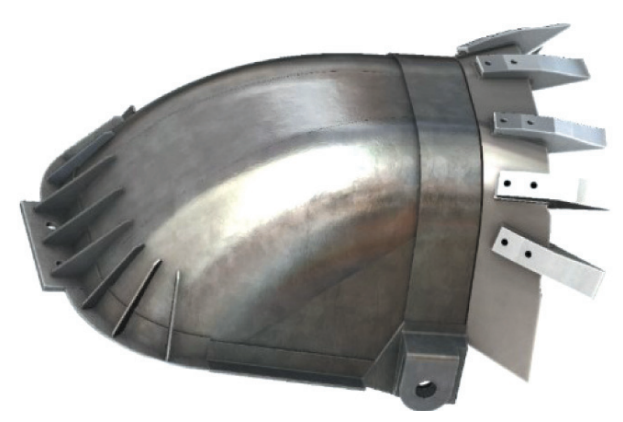

Fig. 4. Bucket with cutting teeth of BWE [8] 


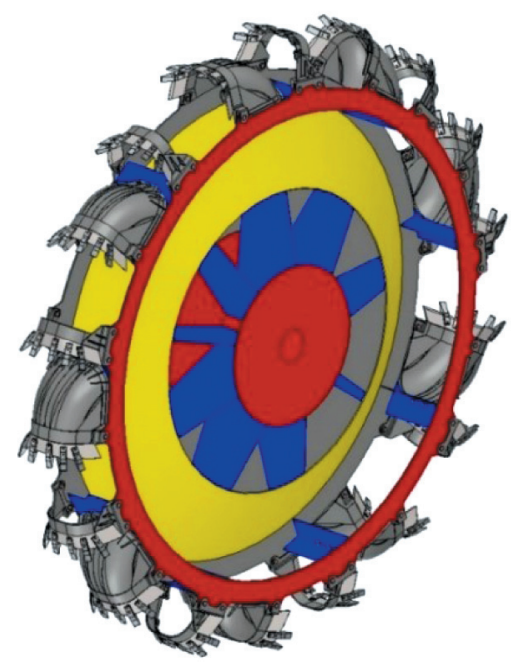

Fig. 5. Rotor assembly of BWE [9]

In Figures 6 and 7, we present a chisel-shaped cutting tooth that is mounted on an $E_{S} R_{C}-1400$-type BWE used in the Oltenia Basin open-pit lignite mines [11]. From the point of view of the geometric parameters, two types of cutting teeth are needed: one for overburden excavation, and the other for lignite excavation. We analyzed the tooth used for lignite excavation; the geometric parameters of these cutting teeth are shown in Table 1 [12].

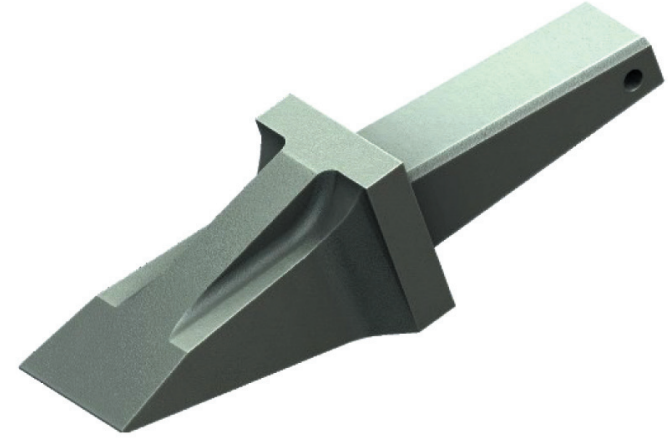

Fig. 6. Chisel-shaped cutting tooth with support bracket used in open-pit coal mines in Oltenia Basin

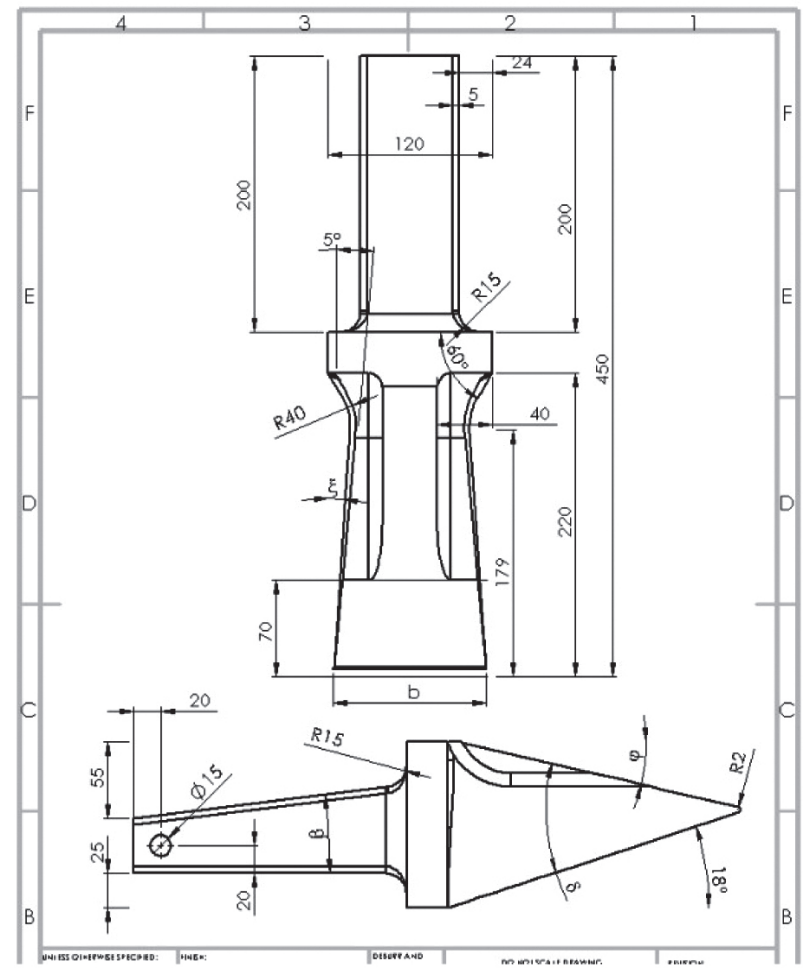

Fig. 7. Geometric dimensions of chisel-shaped cutting tooth with support bracket used in open-pit coal mines in Oltenia Basin

\section{DETERMINATION OF STRAINS AND STRESSES OF CUTTING TEETH USING SOLIDWORKS ${ }^{\circledR}$}

For a realistic approach, the FEM was conducted on an assembly of a cutting tooth and its cup holder support bracket. When creating this assembly, we set up the geometrical links between the two components. Figure 8 shows the restrictions (fixation condition) imposed on the analyzed assembly.

Table 1

Geometric parameters of analyzed cutting teeth (used for lignite excavation)

\begin{tabular}{|c|l|c|c|c|}
\hline No. & \multicolumn{1}{|c|}{ Geometric parameters } & Symbol & Dimensions of cutting tooth ${ }^{\circ}{ }^{\prime}$ & \multirow{2}{*}{ Correlation } \\
\hline 1. & angle of clearance & $\alpha$ & 55 & \multirow{2}{*}{$\alpha+\beta+\delta=90^{\circ}$} \\
\cline { 1 - 3 } 2. & set angle & $\beta$ & 7 & \\
\hline 3. & angle of sharpening & $\delta$ & 28 & \multirow{2}{*}{$\gamma+\alpha=90^{\circ}$} \\
\hline 4. & cutting angle & $\xi$ & 35 & - \\
\hline 5. & longitudinal lateral angle & $\theta$ & 5 & - \\
\hline 6. & transverse lateral angle & $\varphi$ & 3 & - \\
\hline 7. & rake angle & $\mathrm{b}$ & 13 & - \\
\hline 8. & cutting edge width & & 120 & \\
\hline
\end{tabular}




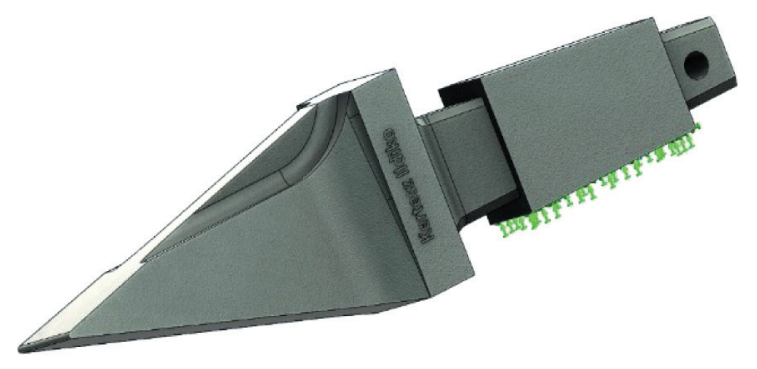

Fig. 8. Fixation conditions of cutting tooth

The maximum tangential and normal cutting forces at the tooth's trajectory were considered as well as the lateral force generated by the pivoting movement [13].

These forces have the following values:

$F_{x}=60 \mathrm{kN} ; F_{y}=18 \mathrm{kN} ; F_{z}=10 \mathrm{kN}$. With respect to the tooth surfaces, we will have the following component forces:

$$
\begin{aligned}
& F_{y 1}=F_{x} \cos \alpha-F_{y} \cos \gamma=25.857 \cdot 10^{3} \mathrm{~N} \\
& F_{x 1}=F_{x} \sin \alpha-F_{y} \sin \gamma=36.198 \cdot 10^{3} \mathrm{~N} \\
& F_{z 1}=10 \cdot 10^{3} \mathrm{~N}
\end{aligned}
$$

For these forces, the state of stresses for a cutting tooth with a sharpening angle of $28^{\circ}$ (which has a leaner construction) were determined. These forces are the resultant forces of specific loads having a random distribution on the active faces of the cutting tooth, which (for our calculations) were considered as applied to the tip of the cutting tooth (Fig. 9).
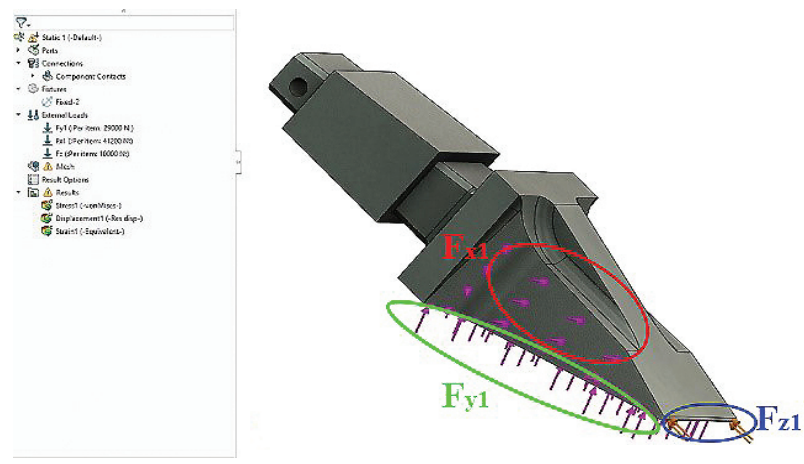

Fig. 9. Forces that act on tooth

The material used for the simulation is $41 \mathrm{MoCr} 11$, or equivalent to $\sigma_{02}=750 \mathrm{~N} / \mathrm{mm}^{2}, \sigma_{r}=950 \mathrm{~N} / \mathrm{mm}^{2}$ (medium hardened alloy steel, recommended for thermal treated parts).
Figure 10 shows the cutting tooth mesh nodal network, and Figure 11 shows the deformations of the cutting tooth resulting from the FEM analysis. It can be noticed that the maximum deformation is $0.665 \mathrm{~mm}$ and occurs at the tip of the cutting tooth.

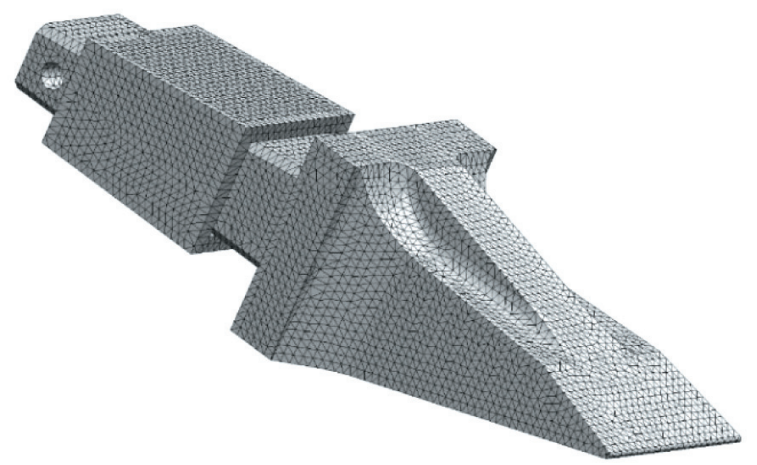

Fig. 10. Mesh nodal network

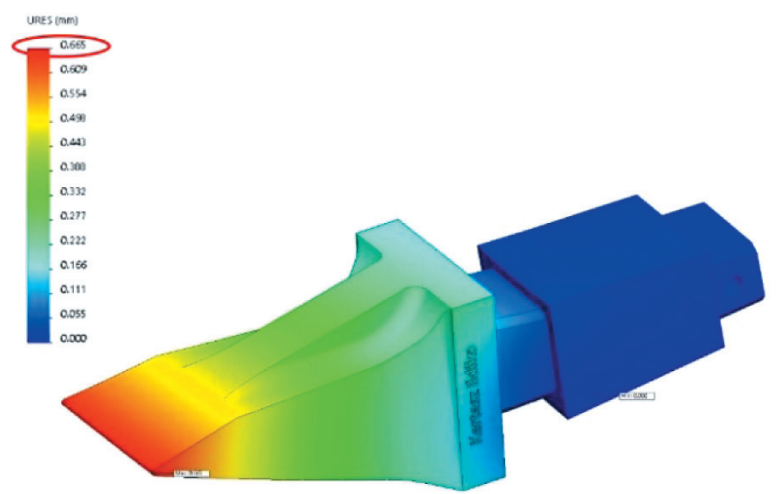

Fig. 11. Deformation of cutting tooth and its cup holder support bracket assembly

Based on Figure 12, it can be observed that the most stress occurs on the tail part of the cutting tooth (between its holder and joint). The maximum von Mises stress is $332 \mathrm{~N} / \mathrm{mm}^{2}$.

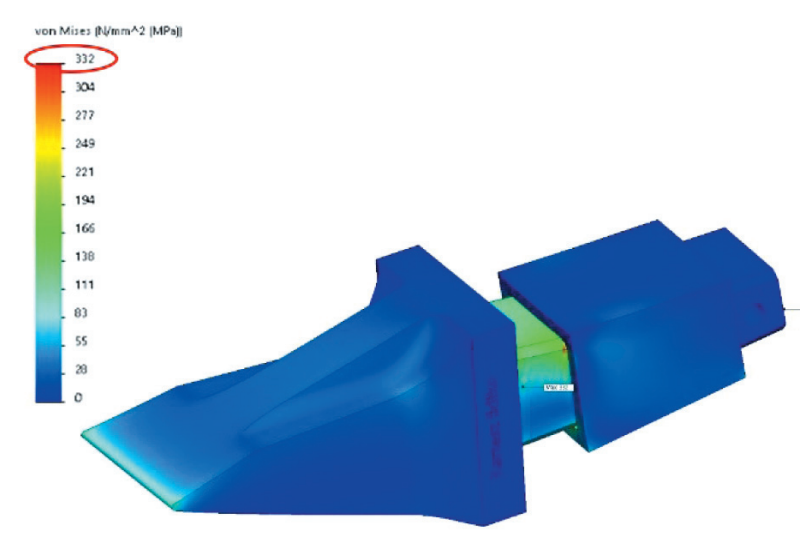

Fig. 12. Stress of the cutting tooth and its cup holder support bracket assembly 


\section{CONCLUSIONS}

FEM is a numerical analysis method that is used to solve problems in various engineering fields. In mechanical engineering, it is widely used for solving structural, vibrational, and thermal problems; and because of its numerical versatility and efficiency, this method imposed itself on the engineering analysis software market while other methods have become niche applications.

FEM/FEA is mainly used during the product-development phase to analyze a project. The ultimate goal of using FEM as a design tool is to change the standard repetitive cycle of design $\rightarrow$ prototype $\rightarrow$ test into a simplified process in which the prototypes are not used as design tools but rather as a validation of the final design.

The use of FEM enables design iterations to shift from the physical space of prototypes and testing into the virtual space of computer simulation.

The simulation of the behavior of cutting teeth mounted on BWEs using FEM was based on the results (obtained over the years by the Department of Mechanical, Industrial, and Transport Engineering) of research contracts aimed at improving the performance of BWEs used in open-pit mining in the Oltenia Basin.

The results obtained using this method are consistent with those determined by analytical methods in the research studies conducted within the MITE Department:

- mounting the cutting tooth into a cup holder causes the von Mises stress to be maximal in the tail area of the tooth, holder, and joint;

- the maximum deformation occurs at the tip of the cutting tooth;

- it is necessary to design a new holder that will better encase the cutting tooth and to carry out a study of the deformations and stresses in this new configuration using simulation and modeling.
References

[1] Dimirache G., Zamfir V.: Ingineria sistemelor mecanice, Editura Focus, Petroşani 2002.

[2] Iliaş N.: Maşini miniere, exemple de calcul, Editura Tehnică, Bucureşti 1993.

[3] Andraş A., Andraş I., Tomuş O.B.: Optimization of geometric and strength parameters of teeth for bucket wheel excavator in view to increasing the cutting efficiency, 17th International Multidisciplinary Scientific GeoConference, SGEM 2017.

[4] Akin J.E.: Finite Element Analysis Concepts via SolidWorks, World Scientific, 2009.

[5] Kurowski P.M.: Engineering Analysis with SOLIDWORKS Simulation, SDC Publications, Mission, USA 2015.

[6] Popescu F.D.: Aplicaţii industriale ale tehnicii de calcul, Editura AGIR, Bucureşti 2009.

[7] Pop I.A., Itu R.B., Radu S.M.: Aplications of forces reduction in the calculation of technological mechanical loads transmited to the tower of a winding engine trough extraction pulley bearings, $16^{\text {th }}$ GeoConference on Science and Technologies in Geology, Exploration and Mining SGEM 2016.

[8] Ladányi G., Virág Z.: Examining the Bucket Wheel Excavator's Bucket After Renewal, "Annals of The University of Petroşani, Mechanical Engineering” 2016, 18: 93-98.

[9] Nan M.S., Kovacs J., Popescu F.D.: Balance control by weighting and tensiometric measurements of bucket wheel excavators, "WSEAS Transactions On Systems And Control" 2008, 11, 3: 927-936.

[10] Marian I.: Utilaje de încărcare şi transport minier, Editura Tehnică, Bucureşti 1991.

[11] Radu S.M., Chmielarz W., Andras A.: Mining Technological System's Performance Analysis, "Annals of the University of Craiova for Journalism, Communication and Management" 2016, 2: 56-64.

[12] Kovacs I., Iliaş N., Nan M.S.: Regimul de lucru al combinelor miniere, Editura Universitas, Petroşani, 2000.

[13] Nan M.S.: Parametrii procesului de excavare la excavatoarele cu rotor, Editura Universitas, Petroşani 2007.

ILDIKO KERTESZ BRINAS, M.Sc., Eng. NARCIS IONEL REBEDEA, M.Sc., Eng. ILIE LUCIAN OLTEAN, M.Sc., Eng. Department of Mechanical, Industrial and Transportation Engineering University of Petrossani 20 Universităţii str. 332006 Petroşani, HD, Romania kerteszildiko@gmail.com 


\title{
Analiza naprężeń i odkształceń zębów tnących koparki wielonaczyniowej $w$ trakcie pracy z wykorzystaniem metody elementów skończonych (MES)
}

\begin{abstract}
W przypadku koparek wielonaczyniowych na proces urabiania maja wptyw sity przeciwstawne elementów roboczych i narzędzi urabiających. Sity te determinują wybór maszyn i ich parametrów oraz metody działania [1, 2]. Badania nad przyczynami awarii części mechanicznych pokazuja, że systemy urabiania i ładowania powoduja najwięcej awarii, około 32\% wszystkich odnotowanych awarii mechanicznych [3]. W niniejszej pracy będziemy używać metody elementów skończonych (MES) do analizy odksztatceń i naprężeń dziatających na ząb tnacy, zamocowany na kole czerpakowym koparek wielonaczyniowych. W tym celu wykorzystano oprogramowanie SolidWorks ${ }^{\circledR}$ - zarówno jako narzędzie CAD do projektowania zęba, jak i do modelowania oraz symulacji zjawisk.
\end{abstract}

Słowa kluczowe: koparka wielonaczyniowa, koło czerpakowe, zęby tnace, uchwyt zębów tnących, MES, siła, naprężenie, odkształcenie

\section{KROKI W ANALIZIE METODĄ ELEMENTÓW SKOŃCZONYCH}

Punktem wyjścia jakiegokolwiek projektu z wykorzystaniem metody elementów skończonych i symulacji jest model, który może stanowić element układu części. Najpierw określa się cechy charakterystyczne materiału (materiałów) części, zadania oraz ograniczenia, którym model jest poddawany [4]. Następnie, wykorzystując dowolne narzędzie oparte na metodzie elementów skończonych, geometrię modelu dzieli się na stosunkowo małe jednostki nazywane elementami skończonymi. Tworzenie elementów jest powszechnie nazywane generowaniem siatki elementów [5].

Stopnie swobody węzła w siatce elementów skończonych określają zdolność węzła do wykonywania translacji i rotacji. Liczba stopni swobody w węźle zależy od typu elementu. W programie SolidWorks ${ }^{\circledR} \mathrm{Si}$ mulation węzły elementów bryły mają trzy stopnie swobody, natomiast węzły elementów skorupy mają sześć stopni swobody.

Tworzenie siatki elementów często wymaga zmian w geometrii CAD:

- kasowanie jest to proces usuwania części geometrii, które są nieistotne podczas analizy, takie jak zaokrąglenia lub skosy;
- idealizacja jest bardziej agresywnym procesem zmiany geometrii, na przykład cienkie ściany są zastępowane przez powierzchnie lub belki zastępowane są przez linie;

- czyszczenie jest niezbędne, aby geometria spełniała wymagania narzucone przez proces generowania siatki.

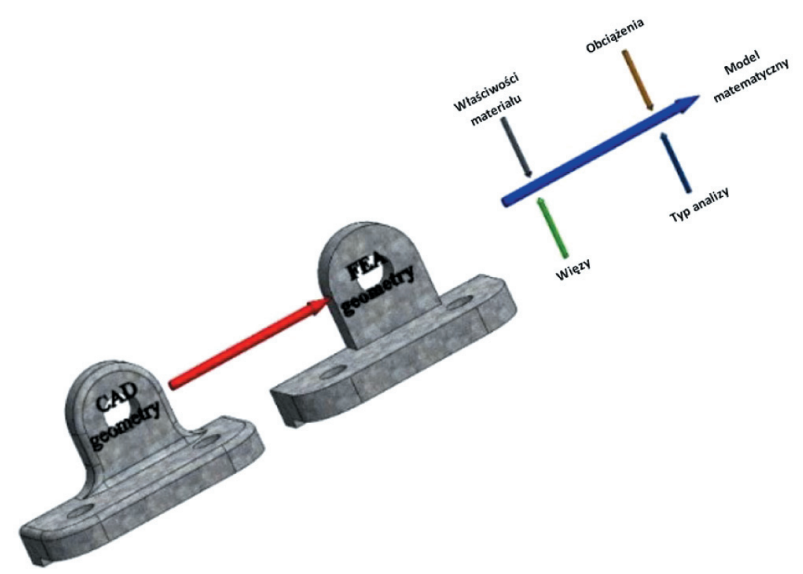

Rys. 1. Tworzenie modelu matematycznego

Na tworzenie modelu matematycznego składa się: modyfikowanie geometrii CAD (tj. usunięto zaokrąglenia - rys. 1), określenie obciążeń i naprężeń, narzucenie ograniczeń, określenie właściwości materiału 
i rodzaju analizy (statyczna, dynamiczna itd.), jaka należy przeprowadzić [6]. Właściwości materiału, zadania i ograniczenia narzucone na model stanowią dane wyjściowe dla określonego typu analizy.

Model matematyczny oparty na geometrii metody elementów skończonych, informacje o materiałach i ich właściwości, wymagania, jakim poddany jest model oraz narzucone ograniczenia, można podzielić na skończone elementy przy użyciu procesu generowania siatki elementów (rys. 2). W odniesieniu do węzłów siatki elementów stosuje się dyskretne obciążenia i ograniczenia [7].

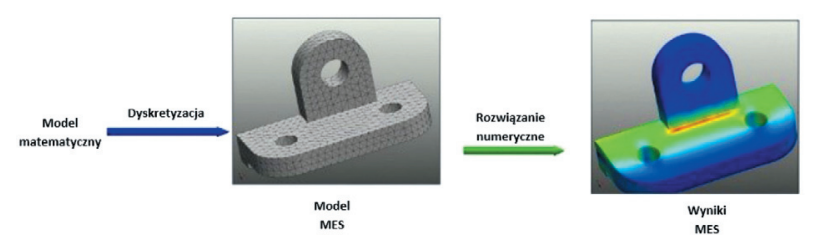

Rys. 2. Budowanie modelu dla metody elementów skończonych

Często najtrudniejszym krokiem badania metody elementów skończonych jest ocena wyników. Poprawna interpretacja wyników oznacza zrozumienie wszystkich uproszczeń i błędów, jakie one wywołują w pierwszych trzech etapach: określeniu modelu matematycznego, generowaniu siatki i rozwiązaniu jej.

\section{KRYTERIUM JAKOŚCI VON MISESA}

Kryterium testu naprężeń von Misesa, znane również jako kryterium Hubera, to test naprężeń, który reprezentuje wszystkie sześć elementów ogólnego stanu 3D (rys. 3).

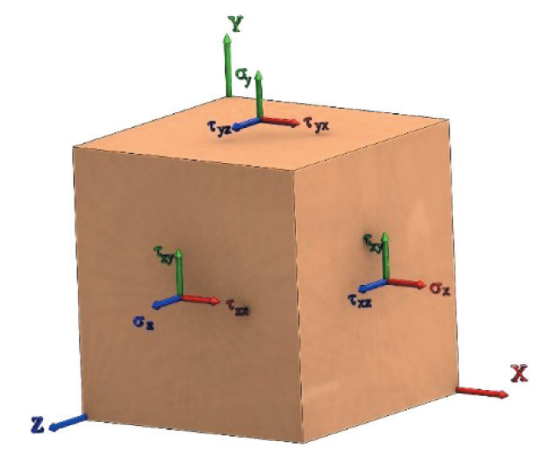

Rys. 3. Geometryczny stan naprężén

Na naprężenie ogólne składają się trzy naprężenia normalne: $\sigma_{x}, \sigma_{v}, \sigma_{z} \mathrm{i}$ sześć naprężeń stycznych. Z uwagi na symetrię naprężeń stycznych ogólny stan naprężenia 3D charakteryzuje sześć elementów: $\sigma_{x}, \sigma_{v}, \sigma_{z}$ i $\tau_{x y}=\tau_{y x}, \tau_{y z}=\tau_{z y}, \tau_{x z}=\tau_{z x}$. Naprężenie von Misesa można wyrazić następującym równaniem:

$$
\sigma_{v m}=\sqrt{\begin{array}{l}
0,5 \cdot\left[\left(\sigma_{x}-\sigma_{y}\right)^{2}+\left(\sigma_{y}-\sigma_{z}\right)^{2}+\right. \\
\left.\left(\sigma_{z}-\sigma_{x}\right)^{2}\right]+3 \cdot\left(\tau_{x y}^{2}+\tau_{y z}^{2}+\tau_{z x}^{2}\right)
\end{array}}
$$

Naprężenie von Misesa używane jest do analizy bezpieczeństwa strukturalnego materiałów o właściwościach elastoplastycznych (takich jak stopy stali lub aluminium). Teoretycznie materiał ciągliwy poddaje się, kiedy naprężenie von Misesa jest równe granicy dozwolonego naprężenia. W większości przypadków jako granicę naprężeń wykorzystuje się granicę płynięcia. Zgodnie z kryterium von Misesa, w przypadku awarii współczynnik bezpieczeństwa $(F O S)$ wyrażony jest jako:

$$
F O S=\frac{\sigma_{\text {limit }}}{\sigma_{v m}}
$$

gdzie $\sigma_{\text {limit }}$ to granica płynięcia.

\section{GEOMETRYCZNE PARAMETRY ZĘBÓW KOPAREK WIELONACZYNIOWYCH}

Na geometrię zębów tnących koparek wielonaczyniowych mają wpływ:

- parametry funkcjonalne koparki,

- parametry konstrukcyjne czerpaków (rys. 4) i koła czerpakowego (rys. 5),

- kształt i rodzaj używanych zębów tnących,

- rodzaj urabianego materiału,

- koszt.

Są dwa rodzaju zębów tnących: zęby tnące w kształcie przecinaka używane w koparkach wielonaczyniowych oraz zęby tnące w kształcie stożka wykorzystywane zarówno w koparkach wielonaczyniowych, jak i kombajnach [10].

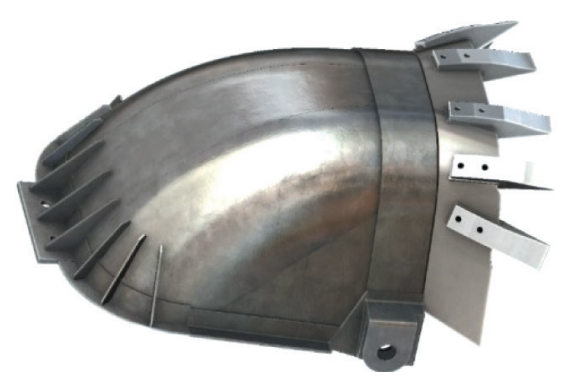

Rys. 4. Czerpak z zębami tnacymi koparki wielonaczyniowej [8] 


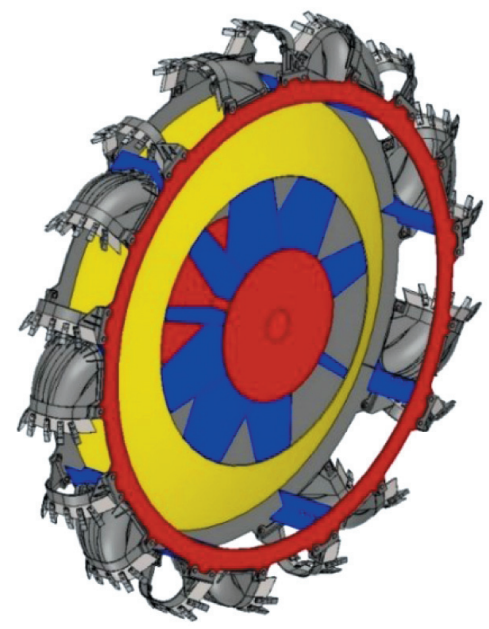

Rys. 5. Zespót koła czerpakowego koparki wielonaczyniowej [9]

Na rysunkach 6 i 7 przedstawiono przecinakowy ząb tnący mocowany na kołowych koparkach wielonaczyniowych typu $\mathrm{E}_{\mathrm{S}} \mathrm{R}_{\mathrm{C}}-1400$, które używane są w kopalniach odkrywkowych węgla brunatnego w zagłębiu Oltenia [11]. Ze względu na parametry geometryczne potrzebne są obydwa typy zębów tnących. Jeden do eksploatacji warstw nadkładowych, a drugi do eksploatacji pokładu węgla brunatnego. W tabeli 1 przedstawiono geometryczne parametry analizowanych zębów tnących [12].

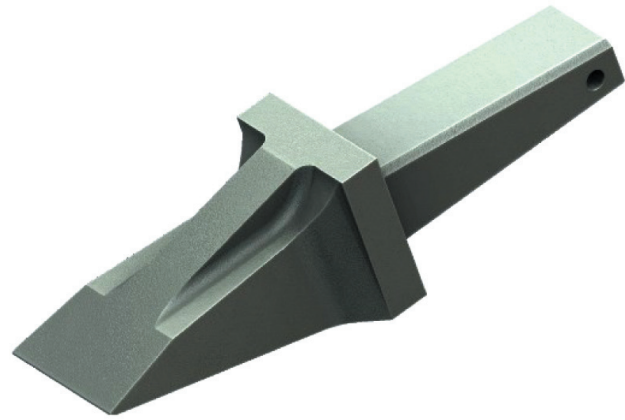

Rys. 6. Ząb tnacy w ksztatcie przecinaka ze wspornikami używany w kopalniach odkrywkowych w zagłębiu Oltenia

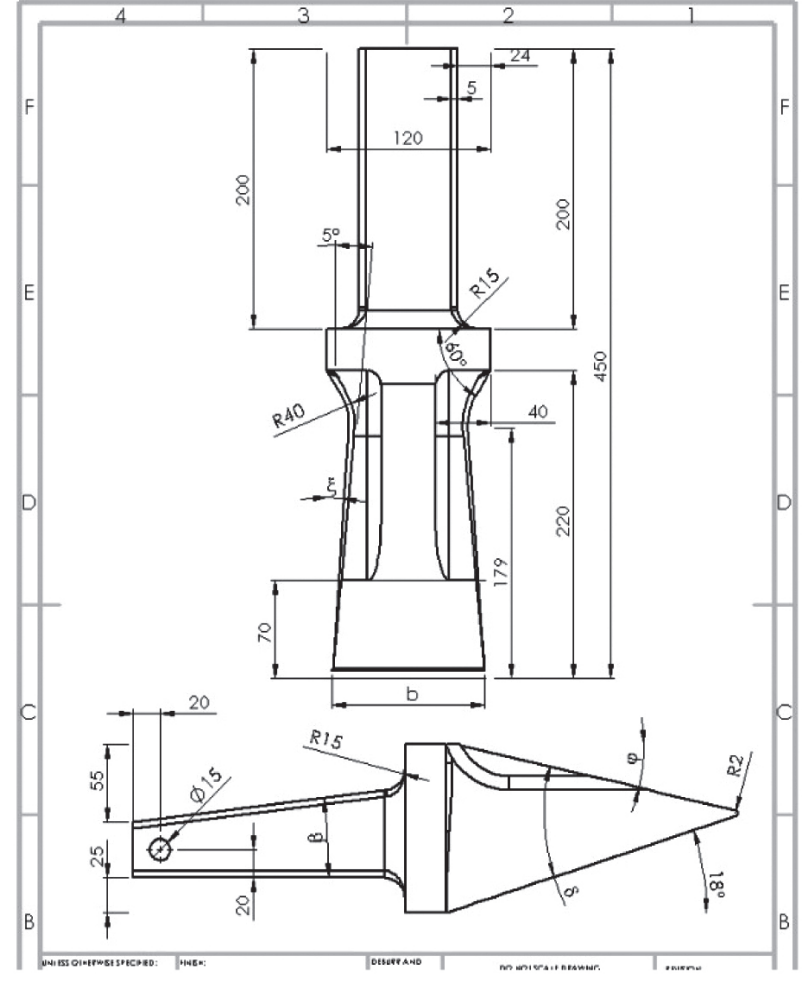

Rys. 7. Wymiary geometryczne przecinakowego zęba tnacego ze wspornikiem,

jaki jest używany w kopalniach odkrywkowych w zagłębiu Oltenia

\section{OKREŚLENIE NAPRĘŻEŃ ZĘBA TNĄCEGO ZA POMOCA SOLIDWORKS ${ }^{\circledR}$}

Przyjmując podejście realistyczne, analizę metodą elementów skończonych przeprowadzono na zespole zęba tnącego i wspornika jego uchwytu. W trakcie tworzenia tego zespołu, skonfigurowano geometryczne połączenia pomiędzy dwoma elementami. Rysunek 8 przedstawia ograniczenia (warunki mocowania) narzucone na analizowany zespół.

Tabela 1

Parametry geometryczne analizowanych zębów tnących (użytych podczas eksploatacji węgla brunatnego)

\begin{tabular}{|c|c|c|c|c|}
\hline $\mathrm{Nr}$ & Parametry geometryczne & Symbol & Wymiary zęba tnącego $\left[{ }^{\circ}\right]$ & Zależności \\
\hline 1. & kąt przyłożenia & $\alpha$ & 55 & \multirow{3}{*}{$\alpha+\beta+\delta=90^{\circ}$} \\
\hline 2. & kąt nastawienia & $\beta$ & 7 & \\
\hline 3. & kąt ostrzenia & $\delta$ & 28 & \\
\hline 4. & kąt cięcia & $\gamma$ & 35 & $\gamma+\alpha=90^{\circ}$ \\
\hline 5. & kąt boczny wzdłużny & $\xi$ & 5 & - \\
\hline 6. & kąt boczny poprzeczny & $\theta$ & 3 & - \\
\hline 7. & kąt zgarniania & $\varphi$ & 13 & - \\
\hline 8. & szerokość krawędzi tnącej & b & 120 & - \\
\hline
\end{tabular}




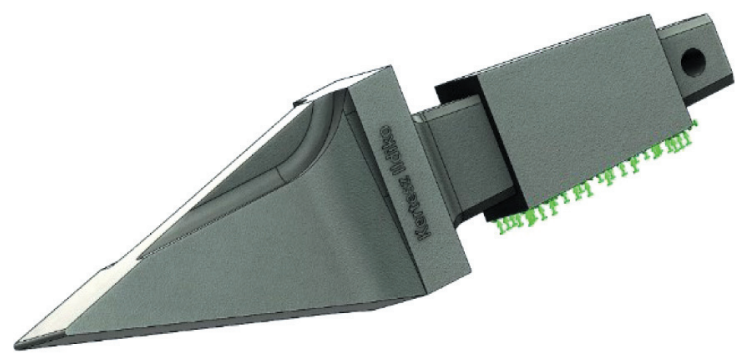

Rys. 8. Warunki mocowania zęba tnacego

Rozważono maksymalne styczne i normalne siły urabiania na trajektorii zęba, jak również jego siłę boczną generowaną przez ruch obrotowy [13].

Siły te przyjmują następujące wartości:

$F_{x}=60 \mathrm{kN} ; F_{y}=18 \mathrm{kN} ; F_{z}=10 \mathrm{kN}$. W odniesieniu do powierzchni zęba będziemy mieć następujące siły składowe:

$$
\begin{aligned}
& F_{y 1}=F_{x} \cos \alpha-F_{y} \cos \gamma=25,857 \cdot 10^{3} \mathrm{~N} \\
& F_{x 1}=F_{x} \sin \alpha-F_{y} \sin \gamma=36,198 \cdot 10^{3} \mathrm{~N} \\
& F_{z 1}=10 \cdot 10^{3} \mathrm{~N}
\end{aligned}
$$

W przypadku tych sił określono stan naprężeń dla zęba tnącego o kącie ostrza $28^{\circ}$, który ma węższą konstrukcję. Siły te to wypadkowe sił obciążeń właściwych o przypadkowym rozmieszczeniu na aktywnych czołach zęba tnącego, które ze względu na obliczenia uznano za zastosowane na ostrzu zęba tnącego (rys. 9).
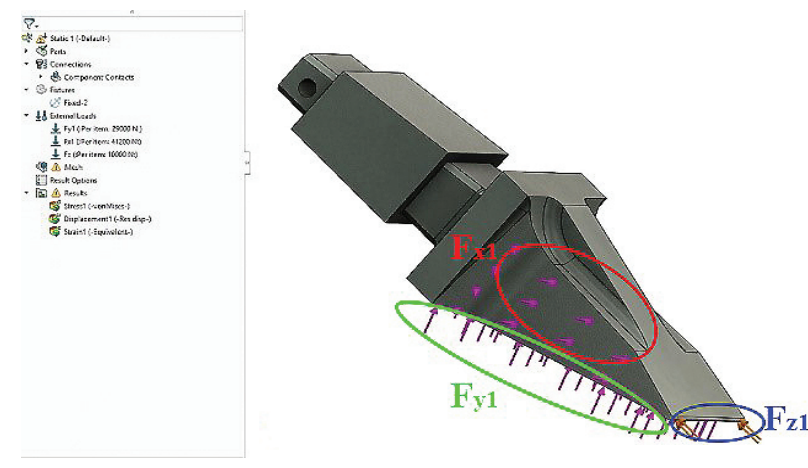

Rys. 9. Sity działajace na ząb

Materiał zastosowany do symulacji to stop $41 \mathrm{MoCr} 11$ lub jego odpowiednik o parametrach $\sigma_{02}=750 \mathrm{~N} / \mathrm{mm}^{2}$, $\sigma_{r}=950 \mathrm{~N} / \mathrm{mm}^{2}$ (średnio utwardzony stop stali, zalecany do części obrabianych na gorąco).

Rysunek 10 przedstawia topologię węzłów siatki zęba tnącego, a rysunek 11 odkształcenia zęba tnące- go wynikające $\mathrm{z}$ analizy przeprowadzonej metodą elementów skończonych. Można zauważyć, że maksymalne odkształcenie wynosi $0,665 \mathrm{~mm}$ i występuje na ostrzu zęba tnącego.

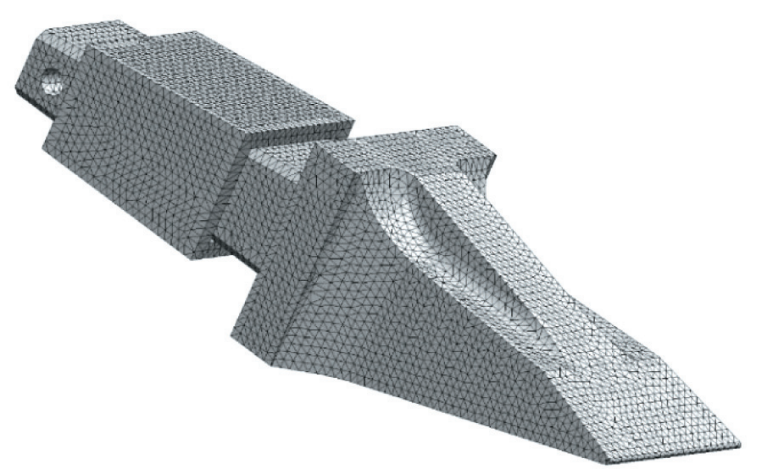

Rys. 10. Topologia węztów siatki

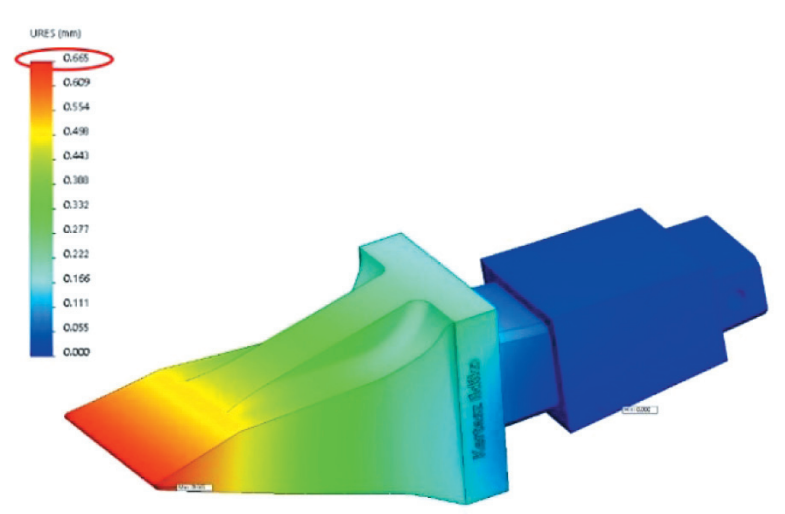

Rys. 11. Odksztatcenie zespołu zęba tnacego $i$ wspornika jego uchwytu

Na podstawie rysunku 12 można zauważyć, że największe naprężenie występuje w części chwytowej zęba tnącego pomiędzy jego uchwytem a łączeniem. Maksymalne naprężenie von Misesa wynosi $332 \mathrm{~N} / \mathrm{mm}^{2}$.

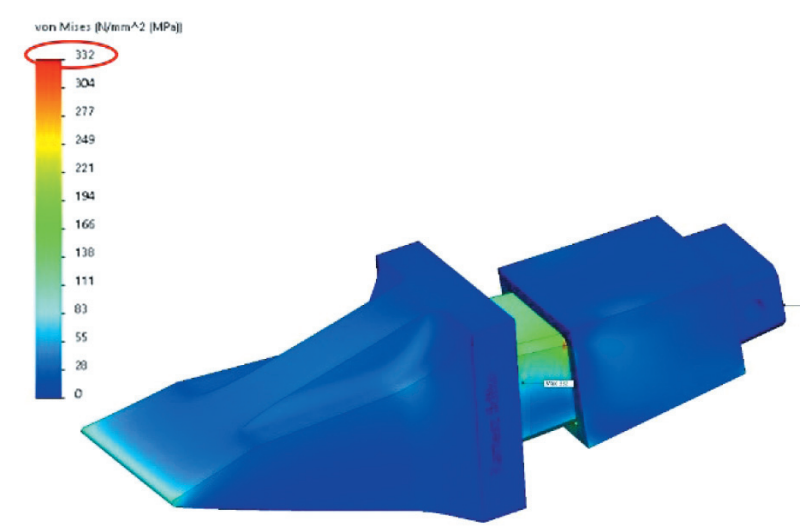

Rys. 12. Naprężenie zespołu zęba tnacego $i$ wspornika jego uchwytu 


\section{WNIOSKI}

Metoda elementów skończonych to analiza numeryczna stosowana do rozwiązywania problemów w różnych dziedzinach inżynierii. W inżynierii mechanicznej jest ona powszechnie używana do rozwiązywania problemów konstrukcyjnych, termicznych i związanych $\mathrm{z}$ wibracjami, a $\mathrm{z}$ uwagi na swoją numeryczną wszechstronność i skuteczność, metoda ta zdobywa popularność na rynku oprogramowania analizy inżynieryjnej, podczas gdy inne metody znalazły tylko niszowe zastosowania.

Metoda analiza elementów skończonych jest stosowana głównie w fazie opracowywania produktu w celu przeanalizowania projektu. Ostatecznym celem jej stosowania jako narzędzia projektowego jest zmiana standardowego powtarzającego się cyklu „projekt $\rightarrow$ prototyp $\rightarrow$ test" na proces uproszczony, w którym prototypy używane są do weryfikacji ostatecznego projektu, a nie jako narzędzia do projektowania.

Dzięki metodzie elementów skończonych wersje projektu przesuwają się z przestrzeni fizycznej prototypów i testowania do wirtualnej przestrzeni symulacji komputerowej.

Symulacja zachowania się zęba tnącego, mocowanego na czerpakach koparek wielonaczyniowych, za pomocą analizy elementów skończonych została oparta na wynikach wieloletnich badań przeprowadzonych w Katedrze Inżynierii Mechanicznej, Przemysłowej i Transportu, których celem była poprawa wydajności koparek wielonaczyniowych używanych w górnictwie odkrywkowym na terenie zagłębia Oltenia. Wyniki uzyskane z wykorzystaniem tej metody są zgodne z rezultatami otrzymanymi przy zastosowaniu metod analitycznych w badaniach naukowych tam prowadzonych:

- mocowanie zęba tnącego w uchwycie powoduje, że naprężenie von Misesa jest maksymalne w obszarze części chwytowej zęba, uchwytu i łączenia;

- maksymalne odkształcenie występuje na ostrzu zęba tnącego;

- należy zaprojektować nowy uchwyt, który zapewni lepszą obudowę zęba tnącego, oraz przeprowadzić badania odkształceń i naprężeń w tej nowej konfiguracji, z wykorzystaniem symulacji i modelowania.
Literatura

[1] Dimirache G., Zamfir V.: Ingineria sistemelor mecanice, Editura Focus, Petroşani 2002.

[2] Iliaş N.: Maşini miniere, exemple de calcul, Editura Tehnică: Bucureşti 1993.

[3] Andraş A., Andraş I., Tomuş O.B.: Optimization of geometric and strength parameters of teeth for bucket wheel excavator in view to increasing the cutting efficiency, 17th International Multidisciplinary Scientific GeoConference, SGEM 2017.

[4] Akin J.E.: Finite Element Analysis Concepts via SolidWorks, World Scientific, 2009.

[5] Kurowski P.M.: Engineering Analysis with SOLIDWORKS Simulation, SDC Publications, Mission, USA 2015.

[6] Popescu F.D.: Aplicatiii industriale ale tehnicii de calcul, Editura AGIR, Bucureşti 2009.

[7] Pop I.A., Itu R.B., Radu S.M.: Aplications of forces reduction in the calculation of technological mechanical loads transmited to the tower of a winding engine trough extraction pulley bearings, $16^{\text {th }}$ GeoConference on Science and Technologies in Geology, Exploration and Mining SGEM 2016.

[8] Ladányi G., Virág Z.: Examining the Bucket Wheel Excavator's Bucket After Renewal, "Annals of The University of Petroşani, Mechanical Engineering" 2016, 18: 93-98.

[9] Nan M.S., Kovacs J., Popescu F.D.: Balance control by weighting and tensiometric measurements of bucket wheel excavators, "WSEAS Transactions On Systems And Control" 2008, 11, 3: 927-936.

[10] Marian I.: Utilaje de încărcare şi transport minier, Editura Tehnică, Bucureşti 1991.

[11] Radu S.M., Chmielarz W., Andras A.: Mining Technological System's Performance Analysis, "Annals of the University of Craiova for Journalism, Communication and Management" 2016, 2: 56-64.

[12] Kovacs I., Iliaş N., Nan M.S.: Regimul de lucru al combinelor miniere, Editura Universitas, Petroşani, 2000.

[13] Nan M.S.: Parametrii procesului de excavare la excavatoarele cu rotor, Editura Universitas, Petroşani 2007.

mgr inż. ILDIKO KERTESZ BRINAS mgr inz. NARCIS IONEL REBEDEA

mgr inż. ILIE LUCIAN OLTEAN

Katedra Inżynierii Mechanicznej, Przemystowej i Transportu

Uniwersytet $w$ Petroszanach

20 Universităţii,

332006 Petroszany, HD, Rumunia kerteszildiko@gmail.com 